\title{
Glucose-Free Fatty Acid Cycle Operates in Human Heart and Skeletal Muscle In Vivo
}

\author{
P. Nuutila, * V. A. Koivisto, ${ }^{\ddagger}$ J. Knuuti," U. Ruotsalainen," M. Terás," M. Haaparanta," \\ J. Bergman," O. Solin,' L.-M. Voipio-Pulkki, “ U. Wegelius," and H. Yki-Järvinen” \\ "Department of Medicine, University of Turku, Turku, Finland; ${ }^{\ddagger}$ Second Department of Medicine, University of Helsinki, SF-00290 \\ Helsinki, Finland; 'Department of Clinical Physiology, University of Turku, Turku, Finland; "Turku Medical Cyclotron-Positron \\ Emission Tomography Center, University of Turku, Turku, Finland; and 'Acceleration Laboratory, Abo Akademi, \\ SF-20520 Turku, Finland
}

\begin{abstract}
Positron emission tomography permits noninvasive measurement of regional glucose uptake in vivo in humans. We employed this technique to determine the effect of FFA on glucose uptake in leg, arm, and heart muscles. Six normal men were studied twice under euglycemic hyperinsulinemic (serum insulin $\sim 500 \mathrm{pmol} / \mathrm{liter}$ ) conditions, once during elevation of serum FFA by infusions of heparin and Intralipid (serum FFA $2.0 \pm 0.4 \mathrm{mmol} / \mathrm{liter}$ ), and once during infusion of saline (serum FFA 0.1 $\pm 0.01 \mathrm{mmol} /$ liter). Regional glucose uptake rates were measured using positron emission tomography-derived ${ }^{18} \mathrm{~F}$ fluoro-2-deoxy-D-glucose kinetics and the three-compartment model described by Sokoloff (Sokoloff, L., M. Reivich, C. Kennedy, M. C. Des Rosiers, C. S. Patlak, K. D. Pettigrew, O. Sakurada, and M. Shinohara. 1977. J. Neurochem. 28: 897-916).

Elevation of plasma FFA decreased whole body glucose uptake by $31 \pm 2 \%(1,960 \pm 130$ vs. $2,860 \pm 250 \mu \mathrm{mol} / \mathrm{min}, P$ $<0.01$, FFA vs. saline study). This decrease was due to inhibition of glucose uptake in the heart by $30 \pm 8 \%(150 \pm 33$ vs. $200 \pm 28 \mu \mathrm{mol} / \mathrm{min}, P<0.02$ ), and in skeletal muscles; both when measured in femoral $(1,594 \pm 261$ vs. $2,272 \pm 328 \mu \mathrm{mol} /$ min, $25 \pm 13 \%)$ and arm muscles $(1,617 \pm 411$ to $2,305 \pm 517$ $\mu \mathrm{mol} / \mathrm{min}, P<0.02,31 \pm 6 \%$ ). Whole body glucose uptake correlated with glucose uptake in femoral $(r=0.75, P<0.005)$, and arm muscles $(r=0.69, P<0.05)$ but not with glucose uptake in the heart $(r=0.04, \mathrm{NS})$.

These data demonstrate that the glucose-FFA cycle operates in vivo in both heart and skeletal muscles in humans. ( $J$. Clin. Invest. 1992. 89:1767-1774.) Key words: positron emission tomography $\bullet$ insulin resistance $\bullet$ glucose transport
\end{abstract}

\section{Introduction}

Positron emission tomography (PET) ${ }^{1}$ is an imaging technique that allows in vivo noninvasive measurement of the concentra-

Address correspondence to Dr. Hannele Yki-Järvinen, Second Department of Medicine, University of Helsinki, SF-00290 Helsinki, Finland.

Received for publication 27 February 1991 and in revised form 3 January 1992.

1. Abbreviations used in this paper: AV, arteriovenous; ${ }^{18} \mathrm{FDG},{ }^{18} \mathrm{~F}$ fluoro-2-deoxyglucose; LC, lumped constant term; PET, positron emission tomography.

J. Clin. Invest.

(C) The American Society for Clinical Investigation, Inc. $0021-9738 / 92 / 06 / 1767 / 08 \quad \$ 2.00$

Volume 89, June 1992, 1767-1744 tion of radiopharmaceuticals labeled with positron emitters (1). With the recent development of a relatively simple method to derive regional metabolic glucose utilization rates from PET data $(2,3)$, quantitation of tissue glucose uptake has become possible $(4,5)$. ${ }^{18} \mathrm{~F}$-fluoro-2-deoxyglucose $\left({ }^{18} \mathrm{FDG}\right)$, which is transported and phosphorylated but not further metabolized, is the most frequently used tracer for the assessment of glucose metabolism $(1,6)$.

Over 25 years ago, Randle and his associates demonstrated an inhibitory effect of FFA on glucose uptake in the perfused rat heart (7). In humans, FFA decrease whole body glucose uptake, especially glucose oxidation during insulin stimulation (8-12). Potential sites for inhibition of glucose oxidation by FFA include heart and skeletal muscle. Since skeletal muscle is responsible for the majority of diminished glucose uptake in various insulin-resistant states $(13,14)$, which also are characterized by abnormalities in FFA metabolism $(15,16)$, it is of interest to determine whether the glucose-FFA cycle operates in this tissue in man.

When the effect of FFA on glucose uptake has been studied in skeletal muscle in vitro, the results have been inconclusive $(7,17-23)$. In the studies of Randle et al. (7, 19, 21), FFA inhibited glucose uptake in rat hemidiaphragm muscle in the absence of insulin and at low insulin concentrations, but had no effect on glucose uptake at high insulin concentrations. Negative results have also been reported in subsequent studies using the same preparation (23), in skeletal muscle fibers $(17,18)$, and in the perfused rat hindquarter (20). Supporting the findings of Randle and co-workers (21), Rennie et al. (22) found a $30 \%$ decrease in glucose uptake in the absence of insulin in perfused rat hindquarters. Recently, Jenkins et al. (24) observed stimulation of glucose uptake and muscle glycogen synthesis by high FFA concentrations in the presence of insulin in vivo in rats. Thus, the interaction between FFA and glucose appear complex and seem to depend on the experimental conditions.

Regarding the heart, Wisneski et al. (25) determined glucose and FFA arteriovenous (AV) differences across the myocardium in normal subjects, and observed a significant inverse relationship between the arterial FFA concentration, and the glucose AV-difference. In addition, the percentage of the arterial glucose concentration that was oxidized was lower at high than at low FFA concentrations (25). While these correlation analyses suggested an interaction between FFA and glucose metabolism, causality remained unproven, since blood flow was not determined. Thus, the quantitative role of FFA in regulating glucose uptake in the human heart remained unclear. Since PET imaging combined with the tracer ${ }^{18} \mathrm{FDG}$ and the model developed by Sokoloff et al. (6) allows quantitation of regional glucose uptake, we used this technique to examine the effects of FFA on heart, arm, and leg muscle glucose uptake in 
humans. To be able to calculate the percentage of glucose uptake accounted for by skeletal and heart muscles, whole body glucose uptake was determined simultaneously using the euglycemic insulin clamp technique.

\section{Methods}

\section{Subjects}

Six normal males (age $29 \pm 1 \mathrm{yr}$, body mass index $23 \pm 1 \mathrm{~kg} / \mathrm{m}^{2}$ ) participated in two studies in random order within one week. The subjects were healthy as judged by history and physical examination and routine laboratory tests, and were not taking any medications. Before the studies, the subjects consumed a weight-maintaining diet containing at least $200 \mathrm{~g}$ of carbohydrate per day for three days.

\section{Study design}

Both studies consisted of a 90 -min basal period and a 120-min hyperinsulinemic period (Fig. 1). In the FFA study, serum FFA were elevated by combined infusions of $20 \%$ Intralipid (Kabi Vitrum, Uppsala, Sweden; $60 \mathrm{ml} / \mathrm{h}$, from -90 to $120 \mathrm{~min}$ ) and heparin (Thromboliquine; Organon, Helsinki, Finland, $200 \mathrm{IU}$ boluses at -90 and $0 \mathrm{~min}$, and a continuous infusion of $15 \mathrm{IU} / \mathrm{min}$ between -90 and $120 \mathrm{~min}$ ). The basal period of $90 \mathrm{~min}$ was included in the protocol as previous studies have demonstrated that exposure of tissues to FFA before insulin administration is necessary to observe changes in whole body glucose and lipid oxidation (26). In the control study, saline $(\mathrm{NaCl})$ was infused instead of Intralipid and heparin. Between 0 and 120 min, whole body glucose uptake was measured under euglycemic hyperinsulinemic conditions (serum insulin $\sim 500 \mathrm{pmol} /$ liter) using the insulin clamp technique as previously described (27).

For measurement of heart and skeletal muscle glucose uptake, ${ }^{18} \mathrm{FDG}$ was injected at 50-60 min, and dynamic scanning was started. Blood samples for measurement of hormone and metabolite concentrations and ${ }^{18} \mathrm{FDG}$ activity were taken as detailed below.

\section{Measurement of whole body glucose uptake by the insulin clamp technique}

All studies were performed starting at 8 a.m. after a $10-12 \mathrm{~h}$ overnight fast. Three catheters were inserted, one in an antecubital vein for infusion of glucose, Intralipid, heparin, and insulin, one in a heated $\left(70^{\circ} \mathrm{C}\right)$ hand vein for sampling of arterialized venous blood, and a third in a contralateral antecubital vein for injection of ${ }^{18}$ FDG.

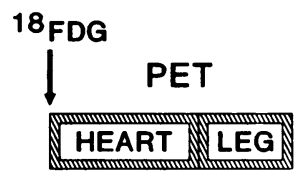

$20 \%$ INTRALIPID AND HEPARIN INFUSIONS /NACL

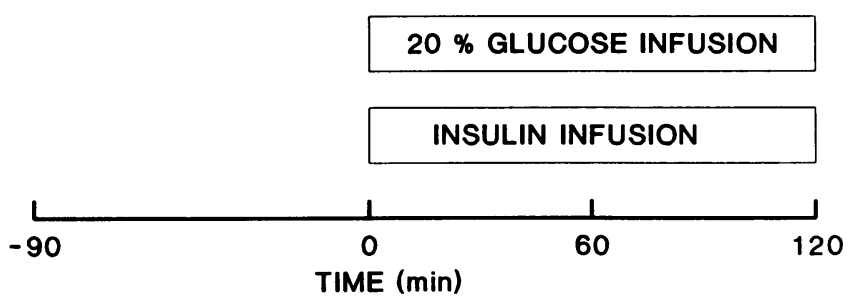

Figure 1. Design of the study. The arrow denotes the time for the ${ }^{18}$ FDG injection. PET heart and leg denote the time periods during which dynamic scans were taken from the thoracic and femoral regions, respectively. $20 \%$ Intralipid and heparin were infused to elevate plasma FFA (FFA study). NACL, saline infusion (control study).
At 0 min, serum insulin was increased for 120 min using a primed continuous infusion of insulin $(26,27)$. The rate of the continuous insulin infusion was $1 \mathrm{mU} / \mathrm{kg}$ per min. During hyperinsulinemia, normoglycemia was maintained using a variable rate infusion of $20 \%$ glucose. The rate of the glucose infusion was adjusted according to the plasma glucose concentration which was measured every $5 \mathrm{~min}$ from arterialized venous blood $(26,27)$. In the present study, $\left[3-{ }^{3} \mathrm{H}\right]$ glucose was not used to quantitate hepatic glucose production rates as the insulin dose employed (1 mU/kg per min) completely suppresses endogenous glucose production (9). Blood samples were taken at 30-min intervals for determination of serum FFA, plasma lactate, and serum insulin concentrations.

\section{Measurement of regional glucose uptake by heart and skeletal muscles using positron emission tomography}

Preparation of ${ }^{18} \mathrm{FDG}$. For two patients ${ }^{18} \mathrm{FDG}$ was synthesized by reacting ${ }^{18} \mathrm{~F}$-labeled acetyl hypofluorite with 3,4,6-tri- $O$-acetyl-D-glucal as described previously (28). The specific activity at the end of synthesis was at least $1 \mathrm{Ci} / \mathrm{mmol}$ for all preparations. The radiochemical purity of ${ }^{18} \mathrm{FDG}$ was better than $97 \%$. For four subjects ${ }^{18} \mathrm{FDG}$ was synthesized using the method of Hamacher et al. (29). The ${ }^{18} \mathrm{~F}-\mathrm{F}^{-}$used in the synthesis had a specific activity of $\sim 150 \mathrm{Ci} / \mu \mathrm{mol}(30,31)$. The radio chemical purity was better than $99 \%$.

Image acquisition. The studies were performed using an eight-ring ECAT 931/08-tomograph (Siemens/CTI Inc., Knoxville, TN) with a spatial resolution of $6.5 \mathrm{~mm}$ (measured value) on the plane and with an axial resolution of $6.7 \mathrm{~mm}$ (measured value, 32). The noise in the PET images was measured by the image uniformity test where the ability of the PET equipment to reproduce the uniform distribution of the homogenous activity of the phantom is determined. The measured coefficient of variation was $8.7 \%$ for direct planes and $7.6 \%$ for cross planes (total collected counts $>30 \times 10^{6}$ ). The subject was positioned in the tomograph first with arms on sides so that the entire heart and the proximal one-thirds of the upper extremities were within the gantry and after that images were obtained from femoral regions. Transmission scannings for correction of attenuation with removable ring source containing germanium were performed for 20-30 min before the emission scannings with total counts of $15-30 \times 10^{6}$ in a plane.

At 50-60 min from starting the insulin clamp, 5-7 mCi of ${ }^{18}$ FDG was injected intravenously over 30-60 s (Fig. 1). Dynamic scanning of the thoracic region was started simultaneously and continued for 40 $\min (8 \times 15 \mathrm{~s}, 2 \times 30 \mathrm{~s}, 2 \times 120 \mathrm{~s}, 1 \times 180 \mathrm{~s}, 6 \times 300 \mathrm{~s})$. Thereafter, five dynamic scans of $300 \mathrm{~s}$ were taken from the femoral region. The average counts during the last 5-min frame obtained from the arm muscles were $60-90 \times 10^{-4}$ counts/pixel per S (SD 10-20\%), from femoral muscles 70-110 $\times 10^{-4}$ counts/pixel per s (SD 8-20\%), and from the myocardium 200-450 × $10^{-4}$ counts/pixel per s (SD 7-20\%). A blood sample for measurement of plasma radioactivity was withdrawn once during each time frame. Radioactivity was measured with a well counter and the value was converted to PET counts using the known calibration factor measured with phantoms.

Image processing. Regions of interest (ROI) analysis was performed on $256 \times 256$ PET reconstructions which were corrected for deadtime, decay and measured photon attenuation. The final in-plane resolution in reconstructed and Hann-filtered images was $\sim 10 \mathrm{~mm} 10 \mathrm{~cm}$ from the center of the gantry. Elliptical ROIs were placed on at least four representative mid-ventricular slices avoiding the myocardial borders. The total number of ROIs was 25-30 (septum, free wall, apex), and size 40-110 pixels/ROI. Correspondingly, ROIs were outlined on the anterior and posterior muscular compartments of the arm (four slices) and on the posterior, anterolateral, and anteromedial muscular compartments of the femoral region (four slices) and their localization was verified by comparison with the position in the transmission images. The number of pixels per ROI in the arm was 80-120, and in the femoral region 140-360.

Corrections applied to time-activity curves. All myocardial time-activity curves were corrected for partial volume effect and spillover ef- 
fect from cavity $(33,34)$. The thickness of the left ventricular wall was assumed to be $10 \mathrm{~mm}$ (35).

Calculation of regional glucose utilization. The differential equations governing the three-compartment ${ }^{18}$ FDG tracer-kinetic model have been described previously $(2,36)$. Plasma and tissue time-activity curves were treated with graphic analysis according to Patlak et al., (3) to quantitate the fractional rate of tracer phosphorylation, $K_{\mathrm{i}}$. The $K_{\mathrm{i}}$ is equal to $\left(k_{1} \times k_{3} / k_{2}+k_{3}\right)$, where $k_{1}$ is the transfer coefficient from vascular space into the tissue, $k_{2}$ is the initial clearance and efflux coeffcient, and $k_{3}$ is the phosphorylation rate constant. The Patlak analysis assumes that the rate of dephosphorylation $\left(k_{4}\right)$ is zero and the tracer is irreversibly trapped in the cell (37). As shown in reference 38 , at least in the heart, $k_{4}$ will become important after $60 \mathrm{~min}$. In the present study, the measurements were done within $65 \mathrm{~min}$ from injection. If in the graphical analysis the plot is linear, for some period, then the underlying assumptions of the method are valid for that period (3). The slope of the plot is equal to the transfer constant $K_{\mathrm{i}}$, representing the fractional rate of tracer phosphorylation. In this study, a minimum of five time points for each region of interest were used to determine the slope by linear regression. The plots between the points were linear (mean $r$ $=0.98 \pm 0.01$ with no difference between the regions). The residuals of the regression lines were stocastically scattered.

The rate of glucose utilization is obtained by multiplying $K_{\mathrm{i}}$ by plasma glucose concentration, [Glc] $]_{p}$, and dividing by a lumped constant term (LC) (6), where rate of glucose utilization $=\left([\mathrm{Glc}]_{\mathrm{p}} / \mathrm{LC}\right)$ $\times K_{\mathrm{i}}$. The lumped constant accounts for differences in the transport and phosphorylation of ${ }^{18} \mathrm{FDG}$ and glucose (2). The LC for myocardium has consistently been found to be equal to 0.67 , and to remain constant despite alterations in ambient glucose and insulin concentrations in rabbit heart $(38,39)$. Furthermore, addition of $1 \mathrm{mmol} /$ liter oleate to the isolated rat heart preparation decreases FDG uptake in the same way as glucose (40). The LC for skeletal muscle has generally been found to be higher than that in the heart and was assumed to be 1.0 (41-44).

The mass of left and right ventricular wall were calculated as described by Devereu and Reichele (35), and Murphy et al. (45), respectively. The measured glucose uptake rates per muscle mass $(\mu \mathrm{mol} / \mathrm{kg}$ muscle per min) in skeletal and arm muscles were converted to whole body glucose uptake rates ( $\mu \mathrm{mol} / \mathrm{min}$ ) assuming $40 \%$ of body weight is muscle in normal weight male subjects (27).

\section{Analytical and statistical procedures}

Plasma glucose was determined in duplicate by the glucose oxidase method (46) using the Glucose Analyzer II (Beckman Instruments, Fullerton, CA). Plasma-free insulin was measured with radioimmunoassay (47) and serum-free fatty acids and plasma lactate with fluorometric methods $(48,49)$. Statistical comparisons between saline and FFA studies were performed using the paired $t$ test and correlation analyses using simple linear regression analysis.

\section{Results}

\section{Glucose, insulin, and free fatty acid concentrations}

Plasma glucose and serum insulin concentrations were comparable in the saline and FFA studies both in the basal state and during hyperinsulinemia (Fig. 2). Serum insulin concentrations averaged $450 \pm 30 \mathrm{pmol} / \mathrm{liter}$ and $468 \pm 42 \mathrm{pmol} / \mathrm{liter}$ during the time when FDG uptake measurements were made (60$120 \mathrm{~min}$ ) in the saline and FFA studies (NS). Basal plasma lactate concentrations averaged $714 \pm 92$ and $738 \pm 96 \mu \mathrm{mol} /$ liter (NS) in the saline and FFA studies. In response to insulin, plasma lactate increased significantly in both studies $(P<0.01$ for both), and was higher in the saline $(1,019 \pm 166 \mu \mathrm{mol} / \mathrm{liter}$, $30-120 \mathrm{~min})$ than the FFA study $(905 \pm 150 \mu \mathrm{mol} / \mathrm{liter}, 30-120$ $\min , P<0.01$ for difference in plasma lactate in saline vs. FFA study).

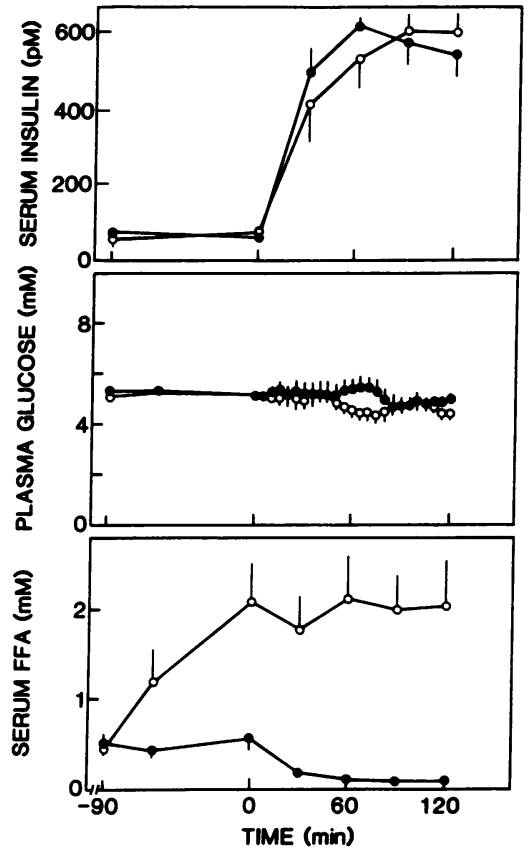

Figure 2. Serum insulin, plasma glucose, and serum free fatty acid concentrations during the saline $(-\bullet-)$ and FFA (-o-) studies.

Effect of FFA on whole body, heart, and skeletal muscle glucose uptake rates

Elevation of plasma FFA decreased the rate of whole body glucose uptake from $2,860 \pm 250$ to $1,960 \pm 128 \mu \mathrm{mol} / \mathrm{min}(P$ $<0.005$, Fig. 3).

When individual PET-derived images of ${ }^{18} \mathrm{FDG}$ uptake were scaled to the same counts per pixel level, ${ }^{18}$ FDG uptake was less in heart and skeletal muscles during FFA study than during saline study (Fig. 4, $A$ and $B$ ). ${ }^{18}$ FDG activity remained $86 \pm 23 \%$ higher $(P<0.01)$ in plasma (example in Fig. 5 ), and lower in skeletal muscle and the heart in each subject in the FFA as compared to the saline study. ${ }^{18} \mathrm{FDG}$ influx constants $\left(K_{\mathrm{i}} \mathrm{s}\right)$ are shown in Table $\mathrm{I}$.

After conversion of the $K_{\mathrm{i}}$ values to glucose uptake rates, FFA inhibited glucose uptake both in the heart and in skeletal muscles (Fig. 3). When expressed per muscle tissue, glucose uptake in whole body decreased from $95 \pm 9$ to $65 \pm 5(P<0.02)$, in the heart from $839 \pm 94$ to $617 \pm 122(P<0.02)$, in femoral muscles from $86 \pm 11$ to $61 \pm 10(P<0.05)$, and in arm muscles from $86 \pm 18$ to $59 \pm 13(P<0.02) \mu \mathrm{mol} / \mathrm{kg}$ muscle per min (Fig. 3).

FFA decreased glucose uptake in whole body by $31 \pm 2 \%$, in the heart by $30 \pm 8 \%$, in femoral muscles by $25 \pm 13 \%$, and in arm muscles by $31 \pm 6 \%$. Thus, the percentage decrease in glucose uptake by FFA was similar in whole body and in all three muscle groups.

When regional glucose uptake rates in heart and skeletal muscle were converted to $\mu \mathrm{mol} / \mathrm{min}$ using the assumptions for skeletal and heart muscle masses described in Methods, skeletal muscle glucose uptake decreased from $2,272 \pm 328$ to $1,594 \pm 261 \mu \mathrm{mol} / \mathrm{min}(P<0.02)$ in the femoral region and from $2,305 \pm 517$ to $1,617 \pm 411 \mu \mathrm{mol} / \mathrm{min}(P<0.02)$ in the arm region, and from $200 \pm 28$ to $150 \pm 33 \mu \mathrm{mol} / \mathrm{min}(P<0.02)$ in the heart. Thus, skeletal muscle explained $\sim 75 \%$ of the decrease in whole body glucose disposal whereas heart muscle explained $\sim 5 \%$. Glucose uptake was $10 \pm 2$ - and $13 \pm 4$-fold higher in heart than in femoral muscles in saline and FFA 


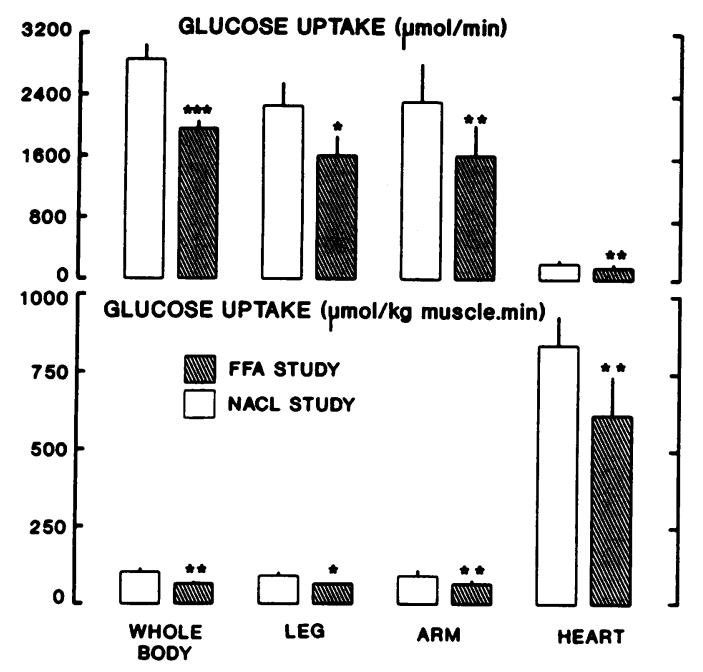

Figure 3. Glucose uptake rates expressed as micromoles per minute (upper panel) and micromoles per kilogram muscle per minute (lower panel) in whole body (measured by the euglycemic clamp technique), leg, arm, and heart muscles (measured by ${ }^{18} \mathrm{FDG}$ and PET) in the FFA (hatched bars) and saline (open bars) studies. ${ }^{*} P<0.05$; ${ }^{* *} P$ $<0.02 ;{ }^{* * *} P<0.005$ for saline vs. FFA study.

studies, and $13 \pm 3-$ and $13 \pm 3$-fold higher in heart than in arm muscles, respectively (Fig. 3). The percentage of whole body glucose uptake accounted for by heart muscle was $7.3 \pm 1.1 \%$ in the saline and $7.7 \pm 1.8 \%$ in the FFA study (NS).

Interrelationships between whole body, heart, and skeletal muscle glucose uptake rates

The relationship between glucose uptake in whole body vs. heart, arm, and femoral muscles is shown in Fig. 6. Whole body glucose uptake correlated with muscle glucose uptake both when measured in femoral $(r=0.75, P<0.005)$, and arm $(r=0.69, P<0.02)$ muscles but not with heart glucose uptake $(r=0.04$, NS) (Fig. 6). The rate pressure product (heart rate multiplied by the systolic arterial blood pressure) was determined in 8 out of the 12 studies, and correlated with heart glucose uptake $(r=0.60, P<0.05)$.

\section{Discussion}

The present data show that free fatty acids inhibit glucose utilization in vivo in humans both in heart and skeletal muscle. Quantitatively, owing to the greater mass of skeletal muscle, inhibition of skeletal muscle glucose uptake by free fatty acids explains most $(\sim 75 \%)$ of the decrease in glucose uptake by free fatty acids.

A factor to consider when using tracer analogues to study metabolic events is the possible difference between the clearance rates of the tracer and tracee. The lumped constant has been used to accommodate these differences. Previously reported values of the lumped constant for tritiated 2-deoxyglucose in skeletal muscle have ranged from 0.8 to $1.2(42-44)$. The lumped constant for the heart and brain for ${ }^{18} \mathrm{FDG}$ has been determined by different methods $(36,39)$. Glucose and ${ }^{18} \mathrm{FDG}$ are more similar structurally than glucose and tritiated 2-deoxyglucose based on the similarities of fluoride and hydrogen (mass, electronaffinity, and hydrogen bond acceptance).
Therefore, the lumped constant for ${ }^{18} \mathrm{FDG}$ in skeletal muscle should be closer to unity than that of 2-deoxyglucose (41). For these reasons we assumed the lumped constant to be 1.0 in the present study. To assess whether the changes in FDG uptake parallel those of unlabeled glucose, separate studies were undertaken to determine the effect of FFA on forearm glucose uptake using a study design identical to that in the present study (49). Data from the two studies are compared in Table II. It is evident that FFA decreased glucose uptake similarly in forearm tissues when measured with the traditional AV-balance technique, and in upper arm and femoral tissues when determined with PET and FDG. These data support the idea that glucose and FDG respond similarly to FFA and that the lumped constant does not change in response to a change in plasma FFA. Regarding the heart, the present data demonstrating an inhibitory effect of FFA on glucose uptake are in keeping with those of Randle et al. (7) in the perfused rat heart as well as the results of Wisneski et al. (25) in the human heart.

Previously, the contribution of skeletal muscle to whole body glucose uptake has been determined by combining the euglycemic insulin clamp technique with the measurement of glucose flux across forearm $(27,49)$ or leg $(50)$ tissues using catheterization techniques. If all muscles in the body are assumed to utilize glucose similarly as leg muscles, $85 \%$ of whole body glucose uptake is accounted for by skeletal muscle when measured using the AV-balance technique across the leg (50). When extrapolated from forearm glucose uptake (27), skeletal muscle accounts for $\sim 70 \%$ of glucose uptake under conditions similar to those employed in the present study. These estimates agree well with those obtained in the present study $(100 \times$ femoral glucose uptake/whole body glucose uptake $=100 \times 2,272 / 2,860=79 \%$, arm/whole body $80 \%$ ) despite the fact that several assumptions have to be made when using either of these techniques. When the AV-balance method is used, the muscle mass of the limb as well as that of whole body is usually assumed rather than measured, as is the fraction of blood flow that flows through muscle tissue (51). With PET and ${ }^{18}$ FDG, glucose uptake is visualized and quantitated in a region of the limb which can easily be identified as muscle tissue. Quantitation of glucose uptake with PET and ${ }^{18} \mathrm{FDG}$ does not allow distinction between changes in glucose uptake attributable to blood flow vs. the glucose AV-difference; on the other hand methodological problems which might be caused by flow measurements do not confound quantitation of glucose uptake. Obviously, unless the muscle mass is determined separately, calculation of the percentage of whole body glucose uptake utilized by muscle tissue may be inaccurate.

Since ${ }^{18} \mathrm{FDG}$ is transported and phosphorylated but not further metabolized intracellularly, the observed decrease in the $K_{\mathrm{i}} \mathrm{s}$ in skeletal muscle and heart was a consequence of either a decrease in glucose transport or phosphorylation, or both. This finding should not be interpreted to imply that glucose metabolism through various pathways distal to transport and/ or phosphorylation became impaired to a similar degree. Previous in vivo studies have shown that free fatty acids impair, under conditions similar to those in the present study, oxidative but not nonoxidative glucose disposal (12). The nonoxidative component of glucose disposal is defined as the difference between the plasma glucose disposal rate and the rate of carbohydrate oxidation (both from plasma glucose and glycogen) as measured with indirect calorimetry, and closely parallels glycogen synthesis under conditions similar to those in the present 
A

HEART

18

FDG

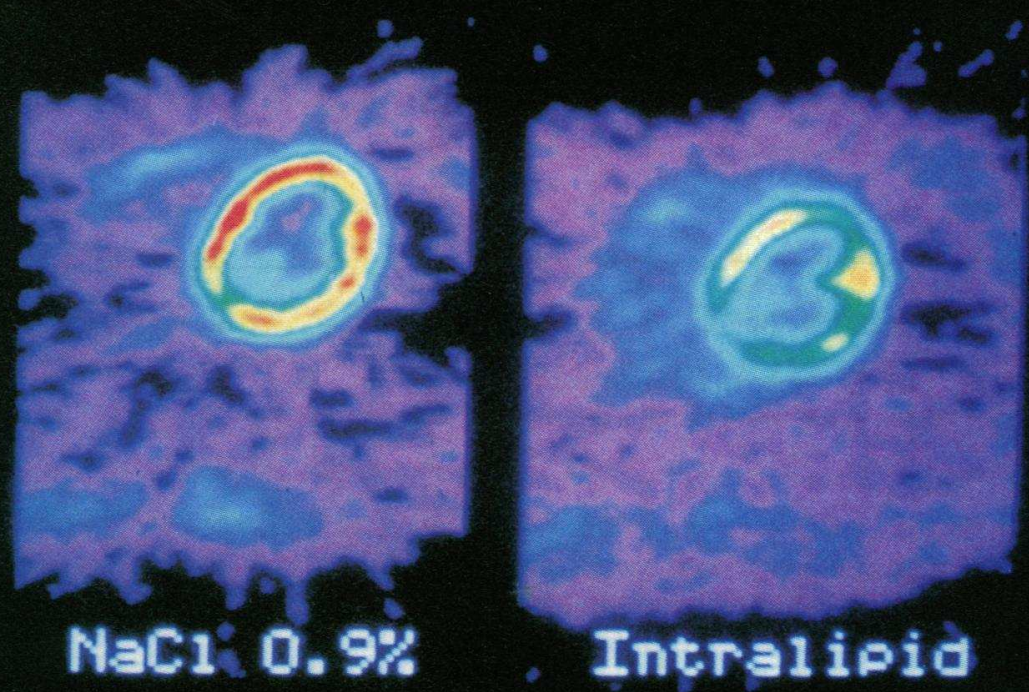

TURKU UNIVERSITY

B

\section{FEMIRRAL REGIDN}
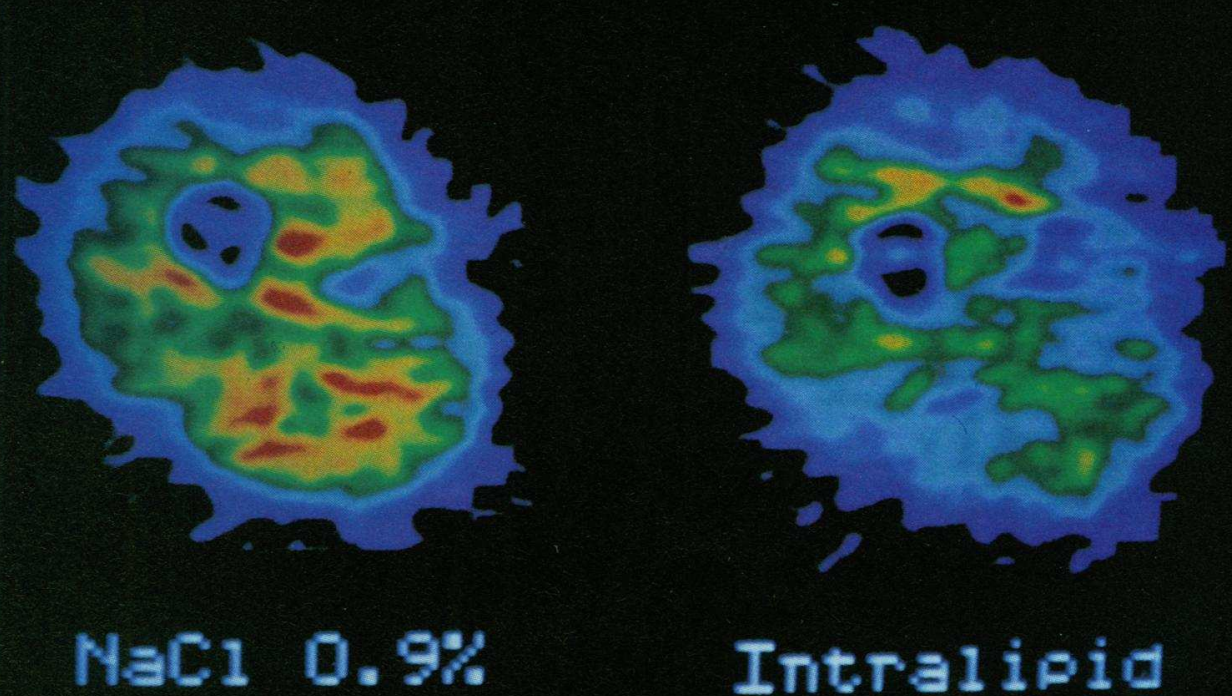

Intralipid

Figure 4. Examples of PET images scaled to the same counts per pixel level from the same subjects participating in the saline ( $\mathrm{NaCl} 0.9 \%)$ and FFA (Intralipid) studies. (A) Heart; (B) femoral region. 


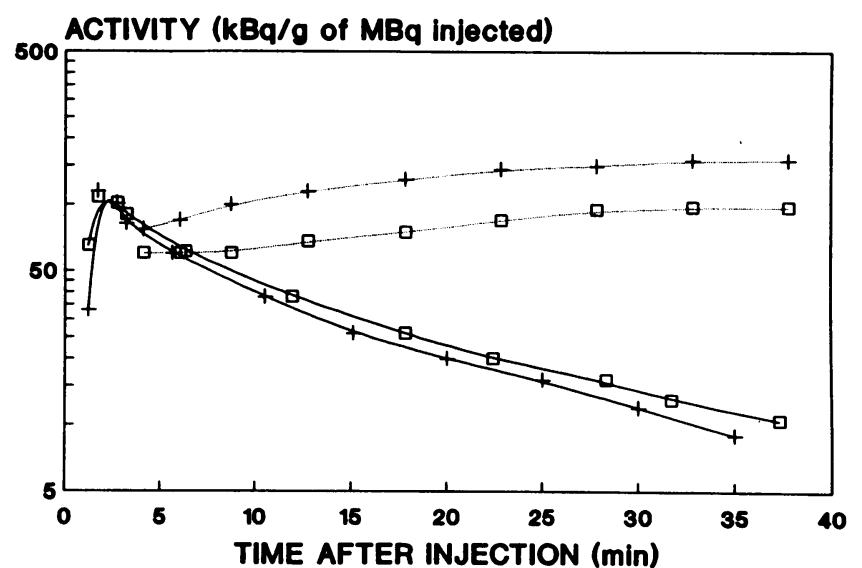

Figure 5. Time-activity curves of ${ }^{18} \mathrm{FDG}$ in plasma (solid lines) and in heart tissue (hatched lines) in the saline $(-+-)$ and FFA (- -$)$ studies.

saline study (14). If, however, glycogen breakdown occurs to a significant extent, plasma glucose oxidation is overestimated and glycogen synthesis underestimated. Therefore, if free fatty acids inhibit glycogenolysis, i.e., have a "glycogen sparing effect" as has been observed during exercise in skeletal muscle (22), the finding of exclusive inhibition of oxidative glucose disposal by free fatty acids may be in error because of limitations in the methodology used in vivo. On the other hand, a close quantitative correspondence exists between the glycogen synthetic rate in skeletal muscle measured by both nuclear magnetic resonance (14) and classic biopsy techniques (13), and the rate of nonoxidative glucose disposal under similar euglycemic hyperinsulinemic conditions as those employed in the present study. These data suggest that glycogenolysis was completely suppressed already in our saline study and thus could not be further suppressed by free fatty acids. These considerations indicate that despite the inhibition of glucose disposal early, i.e., at the level of glucose transport or phosphorylation, free fatty acids do change the fraction of glucose metabolized via oxidative and nonoxidative pathways in skeletal muscle. As previously shown (49), the plasma lactate level was higher during the saline than the FFA study. Since lactate flux from skeletal muscle does not change in response to insulin (52), the higher lactate level in the saline than the FFA study most likely reflects greater glucose utilization in tissues other than muscle (52).

Rennie et al. (22) found accumulation of intracellular glucose in slow-twitch red and fast-twitch red muscle but not in

Table I. Average Kinetic Constants $\left(K_{i}\right)$ during Saline and FFA Studies

\begin{tabular}{lcc}
\hline $\begin{array}{l}\text { Fractional utilization } \\
\text { rate of }{ }^{18} \mathrm{FDG}\end{array}$ & Saline study & FFA study \\
\hline$g_{\text {plasma } / \mathrm{cm}_{\text {tilsur }}^{3} \text { per min }}$ & & \\
Myocardium & $0.123 \pm 0.011$ & $0.088 \pm 0.015^{*}$ \\
Femoral muscle & $0.019 \pm 0.003$ & $0.014 \pm 0.002^{*}$ \\
Arm muscle & $0.019 \pm 0.004$ & $0.013 \pm 0.003^{*}$
\end{tabular}

Values are means \pm SE. Calculations are described in Methods.

* $P<0.05$ for FFA vs. saline study.
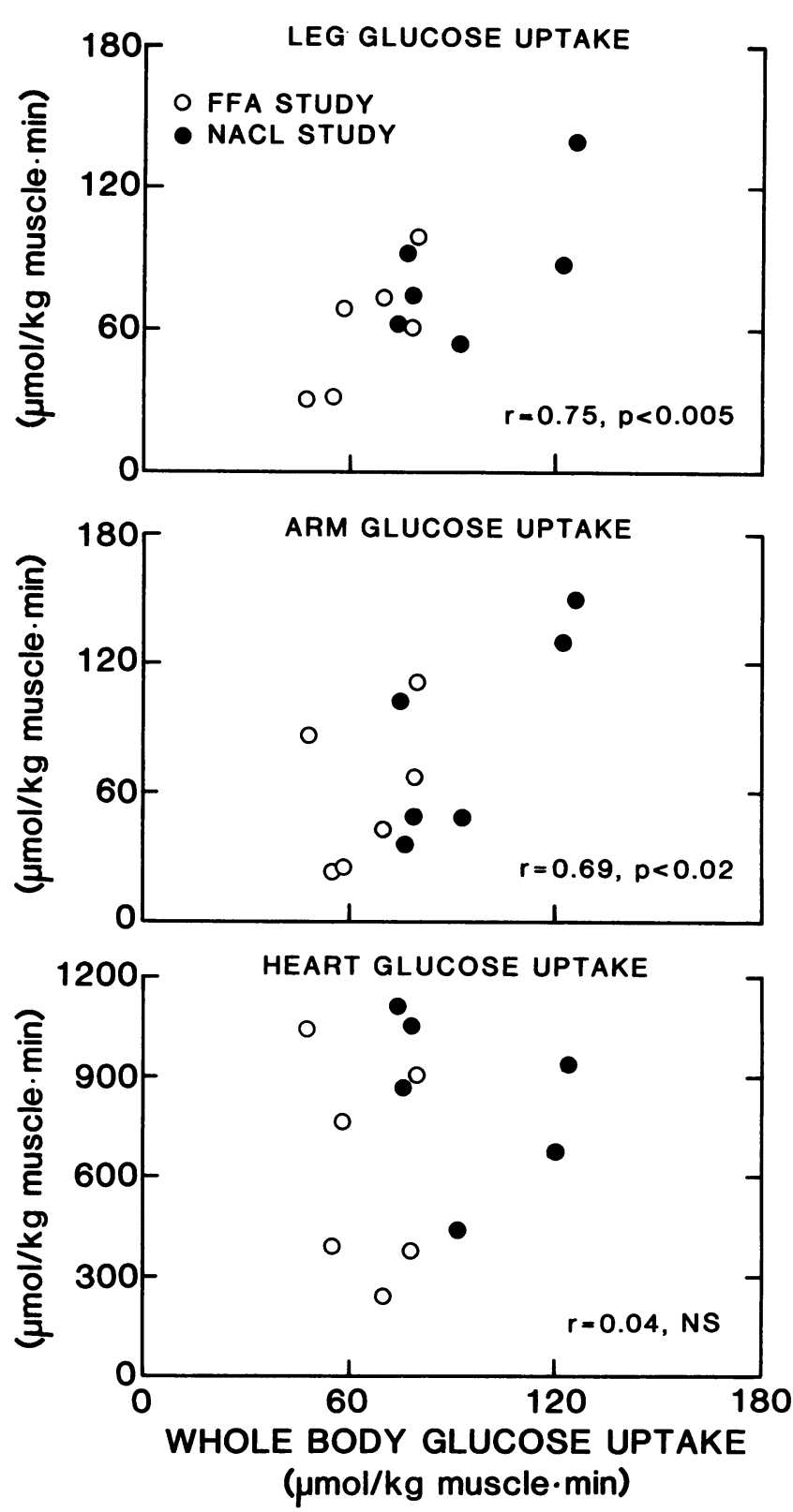

Figure 6. The relationship between whole body glucose uptake and leg, arm, and heart glucose uptake.

white muscle by free fatty acids in the perfused rat hindlimb preparation. This finding suggests inhibition of glucose utilization at the level of phosphorylation. This inhibition was postulated to be mediated via an increase in citrate in red muscle (22). When glucose uptake rates in the present study were determined using ${ }^{18}$ FDG and PET, glucose uptake varied in adjacent areas of the same muscle cross section (Fig. 4, $A$ and $B$ ). As muscle fiber type composition was not determined, we cannot determine the extent if any, of regional variation in glucose uptake due to muscle heterogeneity. The observed variation might, however, explain why needle biopsy specimens taken from vastus lateralis muscle may not always reflect whole body muscle glycogen synthesis (53).

We observed similar relative FFA-induced decreases in glucose uptake in whole body, and heart and skeletal muscle tis- 
Table II. Comparison of Muscle Glucose Uptake Rates Measured with PET in the Present study, and Using the forearm Balance Technique (from Reference 49 with Permission)

\begin{tabular}{|c|c|c|c|c|}
\hline & \multicolumn{2}{|c|}{ PET study } & \multicolumn{2}{|c|}{ Forearm study* } \\
\hline & Saline & FFA & Saline & FFA \\
\hline \multicolumn{5}{|l|}{ Study stubjects } \\
\hline Number of (male) subjects & \multicolumn{2}{|c|}{6} & \multicolumn{2}{|c|}{14} \\
\hline Age $(y r)$ & \multicolumn{2}{|c|}{$29 \pm 2$} & \multicolumn{2}{|c|}{$31 \pm 1$} \\
\hline Body mass index $\left(\mathrm{kg} / \mathrm{m}^{2}\right)$ & \multicolumn{2}{|c|}{$23 \pm 1$} & \multicolumn{2}{|c|}{$24 \pm 1$} \\
\hline \multicolumn{5}{|c|}{$\begin{array}{l}\text { Glucose uptake during hyperinsulinemia } \\
(\mu \mathrm{mol} / \mathrm{kg} B W \text { per } \mathrm{min})^{\ddagger}\end{array}$} \\
\hline Whole body & $38 \pm 3$ & $26 \pm 2^{8}$ & $38 \pm 2$ & $29 \pm 3^{8}$ \\
\hline Arm muscle & $34 \pm 7$ & $24 \pm 5^{1}$ & $31 \pm 4$ & $24 \pm 6^{\prime}$ \\
\hline Femoral muscle & $34 \pm 4$ & $24 \pm 4^{*}$ & \multicolumn{2}{|c|}{ Not determined } \\
\hline
\end{tabular}

The study designs were identical (timing and doses of insulin and Intralipid/heparin infusions) except for the method to determine skeletal muscle glucose uptake. * Data from reference 51 . ${ }^{\star} \mathrm{BW}$, body weight. "Upper arm in PET study, forearm muscle in forearm study. For comparison of the data in the two studies, values for muscle glucose uptake measured with PET expressed as micromoles per kilogram muscle per minute (Fig. 3) were converted to micromoles per body weight per minute by multiplying by 0.4 , i.e., the average fraction of whole body which consists of muscle tissue (28). ${ }^{*} P<0.05,{ }^{\prime} P<0.02,{ }^{\S} P<0.005$ FFA vs. saline study.

sues. This finding does not exclude different effects of free fatty acids on intracellular metabolism in heart as compared to skeletal muscle. Indeed, these tissues are known to differ with respect to their adaptative response to metabolic states characterized by high free fatty acids. For example, fasting (21), and diabetes (53) are associated with increases in cardiac glycogen and glycogen synthesis but decreases in muscle and liver glycogen (54). Despite the increase in glycogen synthesis, total glucose uptake and glucose oxidation are inhibited in the perfused rat heart by high free fatty acids $(21,55,56)$.

Regarding the clinical implications of the present study, the data indicate that insulin resistance can be induced both in the heart and in skeletal muscle by increasing plasma FFA concentrations. Such a phenomenon could occur in patients with non-insulin-dependent diabetes mellitus, in whom free fatty acids are elevated postprandially (57). Although the decrease in skeletal muscle glucose uptake is quantitatively more important for the decrease in whole body glucose disposal in insulinresistant diabetic patients $(13,14)$ as well as in normal subjects exposed to high free fatty acid concentrations (Fig. 3), changes in heart fuel utilization might have long-term adverse effects on, e.g., myocardial function, especially if excessive free fatty acid utilization increases the triglyceride content of heart muscle as has been found in skeletal muscle (58).

\section{Acknowledgments}

This work was supported by grants from the Finnish Academy of Science, Yrjö Jahnsson Foundation, and Nordisk Insulinfond.

\section{References}

1. Phelps, M. E., J. C. Mazziotta, and H. R. Schelbert. 1986. Positron Emission Tomography and Autoradiography: Principles and Application for the Brain and Heart. Raven Press, Ltd., New York.

2. Phelps, M. E., S. -C. Huang, E. J. Hoffman, C. Selin, L. Sokoloff, and D. E. Kuhl. 1979. Tomographic measurement of local cerebral glucose metabolic rate in humans with (F-18)2-fluoro-2-deoxy-D-glucose: validation of method. Ann. Neurol. 6:371-388.
3. Patlak, C. S., and R. G. Blasberg. 1985. Graphical evaluation of blood-tobrain transfer constants from multiple-time uptake data. Generalizations. $J$. Cereb. Blood Flow Metab. 5:584-590.

4. Gambhir, S. S., M. Schwaiger, S. -C. Huang, J. Krivokapich, H. R. Schelbert, C. A. Nienaber, and M. Phelps. 1989. A simple non-invasive quantification method for measuring myocardial glucose utilization in humans employing positron emission tomography and ${ }^{18} \mathrm{~F}$-deoxyglucose. J. Nucl. Med. 30:359-366.

5. Nuutila, P., J. Knuuti, U. Ruotsalainen, M. Teräs, V. Koivisto, U. Wegelius, and L. -M. Voipio-Pulkki. 1990. Glucose uptake in myocardial and skeletal muscle with positron emission tomography in type 2 diabetes (PET). Diabetologia. 33:23A.

6. Sokoloff, L., M. Reivich, C. Kennedy, M. C. Des Rosiers, C. S. Patlak, K. D. Pettigrew, O. Sakurada, and M. Shinohara. 1977. The $\left[{ }^{14} \mathrm{C}\right]$ Deoxyglucose method for the measurement of local cerebral glucose utilization: theory, procedure and normal values in the conscious and anesthetized albino rats. J. Neurochem. 28:897-916.

7. Randle, P. J., P. B. Garland, C. N. Hales, and E. A. Newsholme. 1963. The glucose fatty-acid cycle: its role in insulin sensitivity and metabolic disturbances of diabetes mellitus. Lancet. i:785-789.

8. Thiebaud, D., R. A. DeFronzo, E. Jacot, A. Golay, K. Acheson, E. Maeder, E. Jequier, and J. P. Felber. 1982. Effect of long-chain triglyceride infusion on glucose metabolism in man. Metab. Clin. Exp. 31:1128-1136.

9. Ferrannini, E., E. J. Barrett, S. Bevilacqua, and R. A. DeFronzo. 1983. Effect of fatty acids on glucose production and utilization in man. J. Clin. Invest. 72:1737-1747.

10. Lee, K. U., H. K. Lee, C. S. Koh, and H. K. Min. 1988. Artificial induction of intravascular lipolysis by lipid-heparin infusion leads to insulin resistance in man. Diabetologia. 31:285-290.

11. Bevilacqua, S., G. Buzzigoli, R. Bonadonna, L. S. Brandi, M. Oleggini, C. Boni, M. Geloni, and E. Ferrannini. 1990. Operation of Randle's cycle in patients with NIDDM. Diabetes. 39:383-389.

12. Yki-Järvinen, H., I. Puhakainen, C. Saloranta, and M. -R. Taskinen. 1991. Demonstration of a novel feedback mechanism between FFA oxidation from intracellular and intravascular sources. Am. J. Physiol. 260:E680-E689.

13. Yki-Järvinen, H., K. Sahlin, J. M. Ren, and V. A. Koivisto. 1990. Localization of rate-limiting defect for glucose disposal in skeletal muscle of insulin-resistant type I diabetic patients. Diabetes. 39:157-167.

14. Shulman, G. I., D. L. Rothman, T. Jue, P. Stein, R. A. DeFronzo, and R. G. Shulman. 1990. Quantitation of muscle glycogen synthesis in normal subjects and subjects with non-insulin-dependent diabetes by ${ }^{13} \mathrm{C}$ nuclear magnetic resonance spectroscopy. N. Engl. J. Med. 322:223-228.

15. Groop, L. C., R. C. Bonadonna, S. DelPrato, K. Ratheiser, K. Zyck, E Ferrannini, and R. A. DeFronzo. 1989. Glucose and free fatty acid metabolism in non-insulin-dependent diabetes mellitus: evidence for multiple sites of insulin resistance. J. Clin. Invest. 84:205-213.

16. Taskinen, M. -R., C. Bogardus, A. Kennedy, and B. V. Howard. 1985. Multiple disturbances of free fatty acid metabolism in non-insulin-dependent diabetes. J. Clin. Invest. 76:647-654. 
17. Beatty, C. H., and R. M. Bocek. 1971. Interrelation of carbohydrate and palmitate metabolism in skeletal muscle. Am. J. Physiol. 220:1928-1934.

18. Cassens, R. G., M. Bocek, and C. H. Beatty. 1969. Effect of octanoate on carbohydrate metabolism in red and white muscle of the rhesus monkey. Am.J. Physiol. 217:715-719.

19. Garland, P. B., and P. J. Randle. 1964. Regulation of glucose uptake by muscle. Effects of alloxan-diabetes, starvation, hypophysectomy and adrenalectomy, and of fatty acids, ketone bodies and pyruvate, on the glycerol output and concentrations of free fatty acids, long-chain fatty acyl-coenzyme A, glycerol phosphate and citrate-cycle intermediates in rat heart and diaphragm muscles. Biochem. J. 93:678-687.

20. Goodman, M. N., M. Berger, and N. B. Ruderman. 1974. Glucose metabolism in rat skeletal muscle at rest. Effect of starvation, diabetes, ketone bodies and free fatty acids. Diabetes. 23:881-888.

21. Randle, P. J., E. A. Newsholme, and P. B. Garland. 1964. Regulation of glucose uptake by muscle. Effects of fatty acids, ketone bodies and pyruvate, and alloxan, diabetes and starvation, on the uptake and metabolism fate of glucose in rat heart and diaphragm muscles. Biochem. J. 93:652-665.

22. Rennie, M. J., and J. O. Holloszy. 1977. Inhibition of glucose uptake and glycogenolysis by availability of oleate in well-oxygenated perfused skeletal muscle. Biochem. J. 168:161-170.

23. Schonfeld, G., and D. M. Kipnis. 1968. Effects of fatty acids on carbohydrate and fatty acid metabolism of rat diaphragm. Am. J. Physiol. 215:513-522.

24. Jenkins, A. B., L. H. Storlien, D. J. Chisholm, and E. W. Kraegen. 1988 Effects of nonesterified fatty acid availability on tissue-specific glucose utilization in rats in vivo. J. Clin. Invest. 82:293-299.

25. Wisneski, J. E., E. W. Gertz, R. A. Neese, L. D. Gruenke, D. L. Morris, and J. C. Craig. 1985. Metabolic fate of extracted glucose in human myocardium. J. Clin. Invest. 76:1819-1827.

26. Bonadonna, R., K. Zyck, C. Boni, E. Ferrannini, and R. A. DeFronzo. 1989. Time dependence of the interaction between lipid and glucose in humans. Am. J. Physiol. 257:E49-E56.

27. Yki-Jărvinen, H., A. Young, C. Lamkin, and J. E. Foley, 1987. Kinetics of glucose disposal in whole body and across skeletal muscle in man. J. Clin. Invest. 79:1713-1719.

28. Haaparanta, M., J. Bergman, O. Solin, and D. Roeda. 1984. A remotely controlled system for the routine synthesis of ${ }^{18} \mathrm{~F}$-2-fluoro-deoxy-D-glucose. $\mathrm{Nu}$ klearmedizin. 21:823-826.

29. Hamacher, K., H. H. Coenen, and G. Stöcklin. 1986. Efficient stereospecific synthesis of no-carrier-added 2- $\left[{ }^{18} \mathrm{~F}\right]$-fluoro-2-deoxy-D-glucose using aminopolyether supported nucleophilic substitution. J. Nucl. Med. 27:235-238.

30. Solin, O., J. Bergman, M. Haaparanta, and A. Reissell. 1988. Production of ${ }^{18} \mathrm{~F}^{-}$from water targets, specific radioactivity and anionic contaminants. $R a$ diat. Isot. 39:1065-1071.

31. Bergman, J., K. Aho, M. Haaparanta, A. Reissell, and O. Solin. 1989. Production of ${ }^{18} \mathrm{~F}-$ from $\mathrm{H}_{2} \mathrm{O}$ : specific radioactivity and chemical reactivity. $J$. Labelled Comp \& Radiopharm. 26:143-145.

32. Spinks, T. J., T. Jones, M. C. Gilardi, and J. D. Heather. 1988. Physical performance of the latest generation of commercial positron scanner. IEEE (Inst. Electr. Electron. Eng.) Trans. Nucl. Sci. 35:721-725.

33. Henze, E., S. C. Huang, D. Plummer, E. Hoffman, M. E. Phelps, O. Ratib, A. Najafi, J. Barrio, and H. R. Schelbert. 1981. Retrieval of quantitative information from positron-emission computed tomographic images for cardiac studies with C-11-palmitate. J. Nucl. Med. 22:P21.

34. Schelbert, H. R., E. Henze, H. R. Shon, R. Keen, H. Hansen, C. Selin, S. -C. Huang, J. R. Barrio, and M. Phelps. 1983. C-11 palmitate for the noninvasive evaluation of regional myocardial fatty acid metabolism with positron computed tomography. III. In vivo demonstration of the effects of substrate availability on myocardial metabolism. Am. Heart. J. 105:492-504.

35. Devereu, R. P., and N. Reichele. 1977. Echocardiographic determination of left ventricular mass in man. Circulation. 55:613-618.

36. Huang, S. -C., M. Phelps, E. Hoffman, K. Sideris, C. Selin, and D. Kuhl. 1980. Noninvasive determination of local cerebral metabolic rate of glucose in man. Am. J. Physiol. 238:E69-E82.

37. Dhawan, V., J. R. Moeller, S. C. Strother, A. C. Evans, and D. A. Rottenberg. 1989. Effect of selecting a fixed dephosphorylation rate on the estimation of rate constants and rCMRGlu from dynamic $\left({ }^{18} \mathrm{~F}\right)$-fluorodeoxyglucose/PET data. J. Nucl. Med. 30:1483-1488.

38. Ratib, O., M. E. Phelphs, S. C. Huang, E. Henze, C. E. Selin, and H. R. Selbert. 1982. The deoxyglucose method for the estimation of local myocardial glucose metabolism with positron computed tomography. J. Nucl. Med. 23:577586.

39. Krivokapich, J., S. -C. Huang, C. E. Selin, and M. E. Phelps. 1987. Fluorodeoxyglucose rate constants, lumped constant, and glucose metabolic rate in rabbit heart. Am. J. Physiol. 252:H777-H787.

40. Nguyen Van, T. B., K. A. Mossberg, T. J. Tewson, W. -H. Wong, R. W. Rowe, G. M. Coleman, and H. Taegtmeyer. 1990. Temporal analysis of myocardial glucose metabolism by $2-\left[{ }^{18} \mathrm{~F}\right]$ fluoro-2-deoxy-D-glucose. Am. J. Physiol. 259:H1022-H1031.

41. Mossberg, K. A., R. W. Rowe, T. J. Tewson, and H. Taegtmeyer. 1989. Rabbit hindlimb glucose uptake assessed with positron-emitting fluorodeoxyglucose. J. Appl. Physiol. 67:1569-1577.

42. Ferre, P., A. Leturque, A. -F. Burnol, L. Penicaud, and J. Girard. 1985. A method to quantify glucose utilization in vivo in skeletal muscle and white adipose tissue of the anesthetized rat. Biochem. J. 228:103-110.

43. Meszaros, K., G. J. Bagby, C. H. Lang, and J. J. Spitzer. 1987. Increased uptake and phosphorylation of 2-deoxyglucose by skeletal muscles in endotoxin treated rats. Am. J. Physiol. 253:E33-E39.

44. Burnol, A. -F., P. Ferre, A. Leturque, and J. Girard. 1987. Effect of insulin on in vivo glucose utilization in individual tissues of anesthetized lactating rats. Am. J. Physiol. 252:E183-E188.

45. Murphy, M. L., P. N. Thenabau, N. deSoyza, J. E. Doherty, J. Meade, B. J. Baker, and J. L. Whittle. 1984. Reevaluation of electrocardiographic criteria for left, right and combined cardiac hypertrophy. Am. J. Cardiol. 53:1140-1147.

46. Kadish, A. H., R. L. Little, and J. C. Sternberg. 1968. A new and rapid method for the determination of glucose by measurement of rate of oxygen consumption. Clin. Chem. 14:116-131.

47. Kuzuya, H., P. M. Blix, D. L. Horwitz, D. F. Steiner, and A. Rubenstein. 1977. Determination of free and total insulin and C-peptide in insulin-treated diabetics. Diabetes. 26:22-29.

48. Miles, J., R. Glasscock, J. Aikens, J. Gerich, and M. Haymond. 1983. A microfluorometric method for the determination of free fatty acids in plasma. $J$. Lipid. Res. 24:96-99.

49. Yki-Järvinen, H., I. Puhakainen, and V. A. Koivisto. 1991. Effect of free fatty acids on glucose uptake and nonoxidative glycolysis across human forearm tissues in the basal state and during insulin stimulation. J. Clin. Endocrinol. \& Metab. 72:1268-1277.

50. DeFronzo, R. A., E. Jacot, E. Jequier, E. Maeder, J. Wahren, and J. -P Felber. 1981. The effect of insulin on the disposition of intravenous glucose Results from indirect calorimetry and femoral venous catheterization. Diabetes. 30:1000-1007.

51. Butler, P. C., and P. D. Home. 1987. The measurement of metabolite exchange across muscle beds. Bailliere's Clin. Endocrinol. Metab. 1:863-878.

52. Yki-Järvinen, H., C. Bogardus, and J. E. Foley. 1990. Regulation of plasma lactate concentration in resting human subjects. Metab. Clin. Exp. 39:859-864.

53. Mott, D. M., S. Lillioja, and C. Bogardus. 1986. Overnutrition induced decrease in insulin action for glucose storage: in vivo and in vitro in man. Metab. Clin. Exp. 35:160-165.

54. Cruickshank, E. W. H. 1913. On the production and utilisation of glycogen in normal and diabetic animals. J. Physiol. (Camb.). 47:1-14.

55. Russel, J. A., and W. L. Bloom. 1956. Hormonal control of glycogen in heart and other tissues in rats. Endocrinology. 58:83-94.

56. Shipp, J. C., L. H. Opie, and D. Challoner. 1961. Fatty acid and glucose metabolism in the perfused heart. Nature (Lond.). 189:1018-1019.

57. Reaven, G. M., C. Hollenbeck, C. Y. Jeng, M. S. Wu, and Y. D. Chen 1988. Measurement of plasma glucose, free fatty acid, lactate, and insulin for 24 hours in patients with NIDDM. Diabetes. 37:1020-1024.

58. Falholt, K., I. Jensen, S. Lindkaer Jensen, H. Mortensen, A. Volund, L. G. Heding, P. Noerskov Petersen, and W. Falholt. 1987. Carbohydrate and lipid metabolism of skeletal muscle in type 2 diabetic patients. Diabetic Med. 5:27-31. 